and $1 / 107$. It is regrettable that the authors' considerable effort in searching for metabolic cause of SIDS was let down by some basic mathematics.

LINDSAY J SMITH Wolfson Centre, Mecklenburgh Square,
London WCIN $2 A P$

1 Holton JB, Allen JT, Green CA, Partington S, Gilbert RE, Berry PJ. Inherited metabolic diseases in the sudden infant death syndrome. Arch Dis Child 1991;66:1315-7.

2 Blakemore AIF, Singleton H, Pollitt RJ, et al. Frequency of the G985 MCAD mutation in the general population. Lancet 1991;337:298-9.

3 Matsubara Y, Narisawa K, Tada K, et al Prevalence of K329E mutation in mediumchain acyl-CoA dehydrogenase gene deterchain acyl-CoA dehydrogenase gene determined from

Dr Holton and colleagues comment:

Dr Smith is quite correct in pointing out that our negative results in testing for MCAD deficiency in cultured skin fibroblasts from $\mathbf{7 0}$ cases of SIDS were not incompatible with claims of a true prevalence of $3 \%$. However, our paper made it clear that our claims that the incidence was less than $3 \%$ were based on our findings and those of others, the report of the Lyon group being cited in particular. ${ }^{1}$ In an almost identical study to our own, the French workers found no positive findings in 107 SIDS cases. If our results are combined, the binomial probability theorem indicates that the incidence of MCAD is less than $1.7 \%$ with $95 \%$ confidence, or $2 \cdot 6 \%$ with $99 \%$ confidence. On this basis, our claim was not unreasonable.

Perhaps it would be useful to summarise further work relating to the prevalence of MCAD deficiency in SIDS. Two other studies similar to those referred to above have been completed. In Sheffield, 160 SIDS cases (E Worthy, personal communication) and in Edinburgh 120 cases (G T N Besley, personal communication) were tested for MCAD deficiency, all with negative results. If all our results are pooled (457 cases) the prevalence of MCAD deficiency is calculated to be less than 0.65 or $1.00 \%$, with 95 or $99 \%$ confidence respectively.

Dr Smith concludes that recent reports of population screening for the common MCAD deficiency mutation found carrier frequencies which supported our claim. In addition, the K329E mutation has been sought in DNA extracted from the liver of more than a 100 SIDS cases without finding any homozygotes for the defect. ${ }^{2}$ Although it is important to appreciate that MCAD deficiency is a cause of sudden, unexplained death, the presentation is not typical of SIDS and it is a rare occurrence.

1 Divry P, Vianey-Liaud C, Zabot MT, Bertrand C, Dumoulin R, Carlier MC. Biochemical investigation for fatty acid oxidation defects in children with sudden infant death syndrome (SIDS). Abstracts of the 27th Symposium of the Society for the Study of Inborn Errors of Metabolism. Munich, 1989:186.

2 Chinsky J, Tolsma T, Cowan T, Blitzer M. Medium chain acyl CoA dehydrogenase (MCAD) deficiency and SIDS: an analysis of post-mortem liver samples for the presence of
the common MCAD mutant allele. Am $\mathcal{F ~} \mathrm{Hum}$ Genet $1991 ; 49$ suppl: 183 .

\section{Reducing the risk of cot death}

SIR,-The nationwide campaign urging mothers to lay their babies on their backs to sleep is open to question. It would be unfortu- nate if the leaflets from the Foundation for the Study of Infant Deaths (FSID) ${ }^{1}$ and its counterpart from the Department of Health with the unambiguous slogan 'Back To Sleep' are taken to represent the views of paediatricians generally.

The assertion that 'there is no evidence that babies are likely to choke when lying on their backs' belies the considerable research into gastro-oesophageal reflux and laryngeal spasm, which is one of the major aetiological hypotheses. Altogether $70 \%$ of normal babies have been shown to have reflux during active sleep with 24 hour $\mathrm{pH}$ probes. ${ }^{3} \mathrm{~A}$ high incidence of reflux has also been demonstrated in 'near miss' cases using barium swallows, $\mathrm{pH}$ probes, and isotope milk scans. ${ }^{4} 5$

Because the prone position is unsafe it does not follow that the supine position is safe. This latest $U$ turn merely replaces one bad position with another. All horizontal positions encourage reflux with the risk of laryngeal spasm. What really matters is to raise the head of the cot. All studies of the supine-versusprone position have neglected the important effect of gravity on reflux. The ideal sleeping position is with the head raised ${ }^{5}$ but if babies must lie flat, the side is probably safer than the front or back. Better still, babies' cot mattresses should be wedge shaped.

Many parents are very worried by the risk of a cot death even if they do not voice their fears. The recommendations I have used for many years are:

- Lay your baby to sleep on one or other side, never the front or back

- Prop up the head of the cot by $10-12 \mathrm{~cm}$ $\left(4-5^{\prime \prime}\right)$

- Keep the cot beside your bed in the first six months

- Learn to give the kiss of life

- Get medical advice if your baby is unwell

A nationwide campaign to reduce cot deaths is undoubtedly long overdue. However if it is to succeed, it is important that the recommendations are simple, sensible, and sound. I am seriously concerned about the widely publicised FSID and Department of Health guidelines.

\section{HERBERT BARRIE Parkside Hospital, Wimbeldon SWI9 5 NE}

1 Foundation for the Study of Infant Deaths. Reduce the risks of cot death. London: FSID, 1992.

2 Department of Health. 'Back to sleep', Reducing the risk of cot death. London: HMSO, 1992. (BTSI/E.)

3 Jeffery HE, Heacock HJ. Impact of sleep and effery $\mathrm{HE}$, Heacock $\mathrm{HJ}$. Impact of sleep and movement on gastro-oesophageal reflux in healthy new
66:1136-9.

4 Spitzer AR, Boyle JT, Tuchman DN, Fox WW. Awake apnoea associated with gastrooesophageal reflux: a specific syndrome. $\mathcal{F}$ Pediatr 1984;104:200-5.

5 Herbert JJ, Book LS, Bray PF. Gastrooesophageal reflux in the 'near miss sudden infant death syndrome'. $f$ Pediatr 1978;92: 73-5.

6 Barrie H. Sleeping position and SIDS. $B M \mathcal{F}$ 1989;298:959.

Imposed upper airway obstruction in small children

SIR,-Surveilance of one of the 14 cases described by Samuels and his colleagues ${ }^{1}$ was undertaken in the department of child health in this hospital with their advice and support.
In addition to the videos they describe, we recorded sound as well and found this to be of considerable importance. Although perpetrators do not know that they are being watched, they are certainly aware of the possibility of being interrupted by someone entering the room. They may go to considerable lengths to disguise what they are about and this was certainly true in our case. As a result, it may not be easy to demonstrate what is happening on video alone. Some of the most compelling evidence which led to a successful outcome of the case arose from the ability to compare what we could see being done to the child with what the perpetrator was saying at the time. In addition, the audible change in a child's cry as the airway is obstructed is unmistakable even if the way in which that obstruction is being achieved is subtle.

Samuels and his colleagues describe the very careful preparation required for covert video surveillance. I would also emphasise the importance of continuing support for all the professionals involved, be they doctors, nurses, or police officers. Surveillance may be necessary for many days - all involved are only too well aware of the possible consequences of a few moments inattention, of any failure of communication, or indeed, of inadvertently betraying to the perpetrator that surveillance is being undertaken.

RICHARD ORME Department of Child Health, Royal Devon and Exeter Hospital (Wonford) Barrack Road
Exeter EX 5 SDW

1 Samuels MP, McClaughlin W, Jacobson RR, et al. Fourteen cases of imposed upper airwa

\section{ABC of child abuse}

SIR,-Torn frenula in children have been said to be 'virtually diagnostic' of non-accidental injury (NAI). ${ }^{1}$ However, two recent cases indicate that this is not always so.

The first case was a 1 year old boy, whose sister was attending our casualty department for an unrelated reason. The boy was walking around the waiting room and fell flat onto his face. Examination of the crying child revealed a torn frenulum of the upper lip. The whole incident was witnessed by professional nursing staff and so the innocence of the incident cannot be doubted.

The second case involves the 14 month daughter of the author. After attempting to climb a vegetable rack, my daughter fell backwards, pulling the vegetable rack onto herself. Rapid investigation of the source of the subsequent bleeding confirmed my worst fears-she had a torn frenulum of the upper lip, presumably where it had been caught on the wire basket. I'm afraid that readers will have to take my word as to the innocence of this injury (what self respecting paediatrician would ever dare take such an injury to their local casualty department!). A torn frenulum is classically said to occur when a bottle or spoon is forced into the mouth of a child. This association is probably strong enough to warrant the usual inquiries by the child protection agencies to see if NAI has occurred. However, before guilt of the child carers is assumed, it should be borne in mind that a torn frenulum is no more pathognomonic of 